\title{
Research on the Mental Stress of College Students in Southwest China amid the COVID-19 Epidemic
}

\author{
Yanyu $\mathrm{Xu}^{1}$, Wenlung Chang ${ }^{1 *}$, Lihong Yang ${ }^{2^{*}}$ \\ ${ }^{1}$ School of Education Science, Nanning Normal University, Nanning, China \\ ${ }^{2}$ Yunnan Open University, Kunming, China \\ *Corresponding Authors.
}

\begin{abstract}
:
This study designed related mental health assessment questions to investigate the mental stress of college students in China's southwest region during the epidemic. In this study, college students from 5 universities in southwest China were selected as the research objects. A total of 1890 questionnaires were distributed, and 1812 questionnaires were recovered, with the recovery rate of $95.87 \%$, of which 1808 are valid. The valid rate of the questionnaire is $99.78 \%$. The data on questionnaires were imported into Excel for preliminary screening and processing, and the data were analyzed using the SPSS22.0 software. The enumeration data are expressed by percentage (\%), and X2 test was performed for comparison. $t$ test was used to compare the enumeration data, with $\mathrm{P}<0.05$ representing there is difference. The research results showed that college students in Southwest China generally have different degrees of mental problems, and there are many influencing factors, including the following aspects: (1) It was found that compared with non-medical students, medical students have a lower degree of anxiety; (2) sleep quality. Generally speaking, mental state is closely related to the quality of sleep; (3) The degree of understanding of COVID-19. Students who have a moderate understanding of the epidemic situation are generally more anxious, suggesting that mistakes or limited cognition of COVID-19 can result in negative emotions of students; (4) This study revealed that with the reduction in the frequency of going out per week, the degree of anxiety of college students increases significantly.
\end{abstract}

Keywords: Mental stress, College students, COVID-19 pandemic period, Health.

\section{RESEARCH BACKGROUND}

Since the outbreak of COVID-19, people around the world have been paying attention to the grim epidemic [1]. On January 26, 2020, the National Health Commission issued the "Guiding 
Principles of Emergency Psychological Crisis Intervention Under the COVID-19 Epidemic", in which it is clearly stated that "psychological crisis intervention should be included in the overall epidemic prevention and control, so that the psychological harm caused by the epidemic can be mitigated, and the mental health status of people affected by the epidemic can be learned" [2].

College students are in a critical period of mental growth and development. At present, as domestic epidemic has been put under control, students of universities in the southwest China have returned to schools. However, college students had experienced a special period, when they spent a long time studying and living at home due to the epidemic [3]. The sudden reduction in social activities and the sedentary online classes made it difficult for students to successfully complete the learning tasks and life planning. Facing various stresses, college students have developed negative emotions such as anxiety and irritability due to the lack of security [4-5].

Universities should pay more attention to the mental health of college students in addition to students' academic performance and epidemic, understand the needs of college students during the epidemic, find mental problems in time, and take effective intervention measures as soon as possible, so as to create favorable conditions for college students to return to normal life, and promote the realization of individual planning [6-7]. Therefore, combining the latest scale developed based on the epidemic and the Kessler 6 Scale with the cognition of college students on the epidemic, this study designed related mental health assessment questions to investigate the mental stress of college students in China's southwest region during the epidemic. It is expected to provide reference for universities to offer mental health education for students during the epidemic.

\section{RESEARCH METHODS}

\subsection{Research Objects}

In this study, college students from 5 universities in southwest China were selected as the research objects. A total of 1890 questionnaires were distributed on the "Wenjuanxing" platform, and 1812 questionnaires were recovered, with the recovery rate of $95.87 \%$, of which 1808 are valid. The valid rate of the questionnaire is $99.78 \%$.

\subsection{Research Process}

\subsubsection{Questionnaire survey}

In this study, the "Mental Health Survey" and "Mental Health Evaluation Criteria" scales were selected as the research tools. The survey was conducted from March 2021 to June 2021 in 
the form of online questionnaire, and statistics were made on relevant data.

\subsubsection{Statistical methods}

In this study, the data on questionnaires were imported into Excel for preliminary screening and processing, and the data were analyzed using the SPSS22.0 software. The enumeration data are expressed by percentage (\%), and X2 test was performed for comparison. $t$ test was used to compare the enumeration data, with $\mathrm{P}<0.05$ representing there is difference.

\subsubsection{Investigation tools}

Criteria for mental health assessment.

The mental health was scored using the Likert five-point scale, where 5 points represent extreme non-conformity, 4 points represent non-conformity, 3 points mean moderate conformity, 2 points denote relative conformity, and 1 point for extreme conformity. The range of total points is $10-50$, with $40-50$ points representing health; $30-39$ points denoting mild mental problems; 20-29 points for moderate mental problems; $10-20$ points for serious mental problems [8].

\subsection{Mental Health Survey}

Based upon the Kessler 6 Scale, the mental health assessment questions were revised and designed, involving 10 dimensions, namely "poor self-control, difficulty in decision-making, inattention", "cynicism, dramatic mood swing", "communication barriers", "loneliness", "worrying about the future", "worrying about the epidemic", "worrying about family members", "decadent", "irritable", and "unable to lead a normal life". The Cronbach alpha value of the questionnaire is 0.73 , indicating that the questionnaire has high reliability; the KMO statistic is 0.88 , which is greater than 0.5 , indicating that this questionnaire has good construct validity [9].

\section{RESULTS}

\subsection{The Basic Situation of the Research Objects}

In the questionnaire survey, 840 respondents are females, accounting for $46.36 \%, 972$ respondents are males, accounting for $53.64 \%$, of which 174 are seniors, occupying 9.60\%, 295 are juniors, occupying 16.28\%, 523 are sophomores, making up 28.86\%, and 820 are freshmen, accounting for $45.25 \%$, as shown in Figure 1 and Figure 2. 


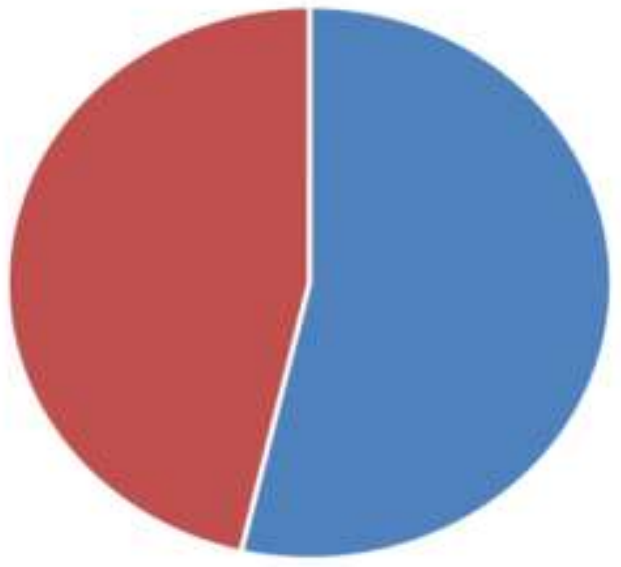

male $=$ female.

Fig 1: Gender distribution

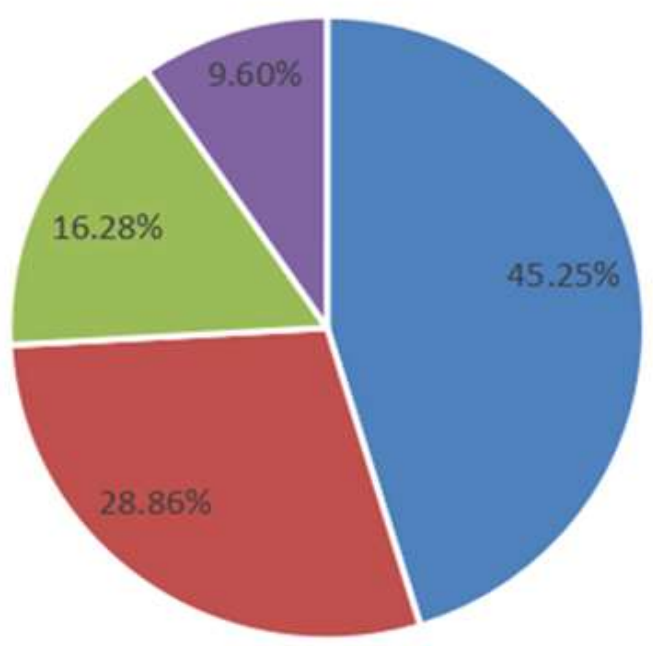

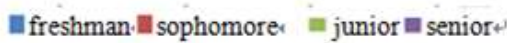

Fig 2: Age distribution

3.2 Mental Health Status of College Students in Southwest China during the Period of the COVID-19 Epidemic 
It was found that during the period of the COVID-19 epidemic, most college students had mild to moderate mental problems, as shown in TABLE I.

TABLE I. Score distribution of the mental health of college students $(n=1812)$

\begin{tabular}{llll}
\hline LEVEL & SCORE & NUMBER $(\mathbf{N})$ & PERCENTAGE $(\%)$ \\
\hline Health & $40-50$ & 300 & 16.56 \\
Mild & $30-39$ & 699 & 38.58 \\
Moderate & $20-29$ & 600 & 33.11 \\
Severe & $10-19$ & 213 & 11.75 \\
\hline
\end{tabular}

3.3 Multi-Factor Analysis of the Mental Status of College Students in Southwest China

In this study, sleep quality, frequency of going out per week, the degree of understanding of COVID-19, and major were selected as independent variables. After values were assigned, Logistic multi-factor analysis was performed. The results showed that the occurrence of adverse mental problems are related to sleep quality, the frequency of going out per week, the degree of understanding of COVID-19, and the major of college students in the southwestern region, as shown in TABLE II and TABLE III.

TABLE II. Values of categorical variables

\begin{tabular}{ll}
\hline INDEPENDENT VARIABLES & METHOD OF ASSIGNING VALUES \\
\hline Sleep quality & Poor $=1 ; \operatorname{good}=0$ \\
The frequency of going out per week & $>3$ times $=2 ; 1-3$ times $=1 ;$ none $=0$ \\
The degree of understanding of COVID-19 & Moderately understand $=1$; understand well $=0$ \\
Major & Non-medical majors $=1 ;$ Medical majors $=0$ \\
\hline
\end{tabular}

TABLE III. Multi-factor analysis of the influencing factors for the mental problems of college students in southwest China

\begin{tabular}{lllll}
\hline INDEPENDENT VARIABLES & B & WALD & P & OR \\
\hline $\begin{array}{l}\text { Sleep quality } \\
\begin{array}{l}\text { The frequency of going out per } \\
\text { week }\end{array}\end{array}$ & 0.422 & 17.536 & $<0.001$ & 1.525 \\
$1-3$ times & -0.327 & 7.285 & 0.006 & 0.722
\end{tabular}


Article History: Received: 10 May 2021 Revised: 20 June 2021 Accepted: 18 July 2021 Publication: 31 August 2021

\begin{tabular}{|c|c|c|c|c|}
\hline$>3$ times & -0.365 & 6.928 & 0.009 & 0.698 \\
\hline $\begin{array}{l}\text { The degree of understanding of } \\
\text { COVID-19 }\end{array}$ & 0.477 & 13.586 & $<0.001$ & 1.615 \\
\hline Major & 0.344 & 12.634 & $<0.001$ & 1.409 \\
\hline
\end{tabular}

\section{DISCUSSION}

College students are in a vital stage of mental growth and development. Suffering anxiety and panic caused by the epidemic, coupled with long-term staying at home, they are prone to mental stress reactions such as worry and loneliness. If the "mental power" is significantly reduced, and cannot be supplemented in a timely manner, students are easily subject to different degrees of negative emotions, which will increase the psychological burden [10-11]. The research results showed that college students in Southwest China generally have different degrees of mental problems, and there are many influencing factors, including the following aspects: (1) major. It was found that compared with non-medical students, medical students have a lower degree of anxiety. The reason may be that the medical students pay more attention to the epidemic. They have a rational view of the domestic epidemic prevention and control, and they know how to respond to the epidemic, thus, they will adjust emotions, and maintain a positive and healthy attitude [12-13]; (2) sleep quality. Generally speaking, mental state is closely related to the quality of sleep [14]. At present, stresses from multiple aspects such as employment and academic performance will aggravate the sleep disorders of college students, especially during the period of epidemic, when students stayed at home. Although most students had a longer sleep, they slept late, leading to negative emotions, which affected night sleep, and the two factors interact to form a vicious circle [15-16]; (3) the degree of understanding of COVID-19. Compared with students who have a full understanding of the epidemic, students who have a moderate understanding of the epidemic situation are generally more anxious, suggesting that mistakes or limited cognition of COVID-19 can result in negative emotions of students. Therefore, health education should be strengthened to enhance students' awareness of diseases [17]; (4) Frequency of going out per week. This study revealed that with the reduction in the frequency of going out per week, the degree of anxiety of college students increases significantly. The result is consistent with the research reports of Lu Boyi [18] and Xu Fei [19]. The reason is that students could not go out at will during the period of epidemic, forcing them to change daily habits. As they stayed at home for a long time, students gradually developed resistance, thereby aggravating mental problems [20].

\section{CONCLUSION}

In summary, during the period of COVID-19 epidemic, college students in southwestern China generally had different levels of mental problems, which are related to many influencing 

pay attention to their emotional needs, strengthen communication, guide them to vent their negative emotions through appropriate ways, and correct their bad lifestyles and habits, so as to help students to develop a healthy lifestyle, and maintain a positive attitude.

\section{References}

[1] Yang Q, Liu QG, Wang JB, Zhang C, Shen YH, You SH (2021) Relationship Between Resting Heart Rate And Physical Activity Mode In College Students After Covid-19: 54. Medicine \&amp; Science in Sports \&amp; Exercise, 53 (8S Suppl 1)

[2] Wang SG (2021) Reflections on the mental health of college students in the context of COVID-19. Journal of Career Academy, Jiamusi, 37 (07): 121-122

[3] Zhang F, Liu Y, Wang MX, Wei XQ, Chen GX, Liu WJ (2021) Relationship between state anxiety and subjective well-being of college students during the epidemic of new crown pneumonia: mediating effect of hope. psychology, technology and application, 9 (07): 432-439

[4] Du QG, Zhu SK, Zeng LM, Deng YY, Du YH, Wu NN (2021)The influence of personality traits on depression in COVID-19: the mediating effect of resilience. Psychological monthly, 16 (13): $23-25+56$

[5] Qiu J, Yu HJ (2021) The Impact Of Covid-19 On Sedentary Behavior Among Chinese College Students: 557. Medicine \&amp; Science in Sports \&amp; Exercise, 53(8S Suppl 1)

[6] Sun M, Hao CY, Di XY, Li XD, Wang Y (2021) Investigation and analysis of mental health status of college students in Jinzhou during normal prevention and control of COVID-19 and its influencing factors. Journal of Jinzhou Medical University (SOCIAL SCIENCE EDITION), 19 (03): 65-69.

[7] Jiang JC, Song ZY, Wang HY. (2021) Investigation and analysis of mental health status of vocational college students during the period of new crown pneumonia outbreak. Journal of Shanxi energy University, 34 (03): 28-30.

[8] Shu ML, Liao XY, Qin LL. Mental health status and influencing factors of college students in Changsha in the post epidemic era. Chinese Journal of Health Psychology: 1-12

[9] Liu HJ, Chen J, He ZM. (2021) The mental health status and influencing factors of college students during COVID-19 period. China Safety Science Journal, 31 (05): 168-173

[10] Jaclyn D, Lucas C, Gary P, Kara W (2021) Physical Activity and Sedentary Behavior in College Students during the Covid-19 Pandemic: 551. Medicine \&amp; Science in Sports \&amp; Exercise, 53(8S Suppl 1)

[11] Case J, Lauren A, Ludmila CL (2021) Effects of the Covid-19 Pandemic on The Fitness Routines Of College Students And Faculty: 209. Medicine; Science in Sports; Exercise, 53(8S Suppl 1)

[12] Zhou HL, Chen Y. The impact of the "four in one" mental health service system on the mental health of higher vocational college students during the epidemic prevention and control period. Southern journal, 2021 (05): 96-100

[13] Guo YJ, Wu ZK, Li YX. Investigation and Analysis on physical and mental health of college students in the new crown pneumonia period. stationery and technology, 2021 (06):

[14] Xu WQ, Li GY (2020) Novel coronavirus pneumonia in different periods of independent college students mental health status and differences analysis. Psychological monthly, 15 (19): 83-84 
[15] Morgan Amy L., Ludy Mary Jon, Nieschwitz Natalie C., Huzyak Madelyn G., Du Chen, Tucker Robin M.. (2021) Physical Activity Patterns of College Students during the Early Stages of the Covid-19 Pandemic: 624. Medicine \& Science in Sports \& Exercise, 53(8S Suppl 1)

[16] Shao S, Xiao M (2021) COVID-19 vocational students mental health status analysis and Educational Countermeasures -- a vocational college as an example. Journal of Ezhou University, 28 (03): 41-44.

[17] Liu CB, Zhang YJ (2021) Roll into the system: the impact of epidemic risk on College Students' employment values. Jiang Han academic, 40 (04): 5-13

[18] Lv BY, Zhao ZJ novel coronavirus pneumonia in Vocational Colleges Students' Mental Health Survey and analysis. Forum on Educational Sciences, 2020 (27)

[19] Xu F, Chen YL, he XL (2020) Investigation and analysis of mental health status of college students during COVID-19 period. Journal of Taishan University, 42 (05): 129-136

[20] Wang XQ, Li Q (2020) Analysis of the psychological condition of college students during the period of new crown pneumonia outbreak. Medical dietotherapy and health, 18 (12): 213+215 